Article publié par le Laboratoire de Construction en Béton de l'EPFL

Paper published by the Structural Concrete Laboratory of EPFL

\begin{tabular}{|l|l|}
\hline Title: & Enhancing Punching Strength and Deformation Capacity of Flat Slabs \\
\hline Authors: & Cantone R., Fernández Ruiz M., Bujnak J., Muttoni A. \\
\hline Published in: & ACI Structural Journal \\
\hline $\begin{array}{l}\text { Volume: } \\
\text { Pages: }\end{array}$ & $\begin{array}{l}116 \\
261-274\end{array}$ \\
\hline Year of publication: & 2019 \\
\hline Type of publication: & Peer reviewed journal article \\
\hline
\end{tabular}

Please quote as:

Cantone R., Fernández Ruiz M., Bujnak J., Muttoni A., Enhancing Punching Strength and Deformation Capacity of Flat Slabs, ACI Structural Journal, 116, 2019, 261-274. 


\title{
Enhancing Punching Strength and Deformation Capacity of Flat Slabs
}

\author{
by Raffaele Cantone, Miguel Fernández Ruiz, Jan Bujnak, and Aurelio Muttoni
}

Punching reinforcement systems have significantly developed in recent years as they allow enhancing the punching resistance of slab-column connections as well as their deformation capacity. These systems, with varying geometry and layout, normally consist of vertical or inclined shear reinforcement with both ends anchored on the compression and tension side of the slab. For very high levels of load, when even common punching reinforcement systems cannot safely ensure the transfer of loads, steel shear heads are usually embedded in the slab to enhance the resistance of the connection. Yet, shear heads might be expensive and difficult to place in construction sites.

Following the principle of the dowel action of the compression reinforcement, this paper introduces a novel system to efficiently reinforce slabs against punching shear by using large-diameter double-headed studs acting as shear dowels. This system enhances the performance of shear-reinforced slabs with respect to conventional solutions and might be an efficient alternative to shear heads for a large number of practical situations. The system is validated by means of a specific experimental program including 11 axisymmetric punching tests on interior slab-column connections. The results demonstrate not only the increase of the punching strength but also the deformation capacity of the connection. It is also shown that the system can be consistently designed accounting for the doweling forces by making use of the theoretical frame of the Critical Shear Crack Theory (CSCT), allowing to understand the activation of the shear dowels on the basis of the deformation of the member.

Keywords: Critical Shear Crack Theory; dowel action; experimental tests; flat slabs; punching; shear reinforcement.

\section{INTRODUCTION}

Despite the redundancy and robustness in bending of reinforced concrete flat slabs, these structural elements include sensitive regions in which stress concentrations may occur due to the interaction between high flexural and shear demands at the slab-column connections, leading to potentially brittle failures in punching. In the last 60 years, significant improvements on the understanding of the mechanics involved in punching shear failures of slab-column connections have been achieved, comprising both experimental and analytical works. ${ }^{1,2}$ Failures in punching of slabs without transverse reinforcement occur by development of a conical failure surface originated at the supported area (Fig. 1(a)). In actual continuous slabs supported on columns, these shear failures usually occur at load levels below that of the flexural resistance of the slab ${ }^{3,4}$ and develop in a brittle manner. To enhance the performance of slab-column connections, punching shear reinforcement is usually arranged as transverse reinforcement in the form of stirrups or headed studs. Failures can then still occur in punching by crushing of the concrete struts (Fig. 1(b)), development of a conical failure surface within the shear-reinforced area (Fig. 1(c)), or by punching outside the shear-reinforced area (Fig. 1(d)). In any of these cases, the strength and deformation capacity of the slab can be significantly increased by allowing for redistributions of internal forces and further activating membrane action. ${ }^{3,4}$

The increase on the performance of shear-reinforced slabs is nevertheless limited by the crushing of the compression struts (depending significantly on the anchorage and detailing rules of the punching reinforcement ${ }^{5}$ ), which defines the maximum achievable punching strength for a given system. For higher load levels, and when increasing the dimensions of the slab and column are not possible, it is normally necessary to embed steel shear heads within the slab (one instance of steel shear head is shown in Fig. 1(e)). Nevertheless, shear heads also present some drawbacksfor instance, the relatively high cost and the increased difficulties during construction.

Within this context, in this paper, a new punching shear reinforcing system is introduced, allowing to significantly enhance the strength and deformation capacity of slabcolumn connections but without the need of arranging embedded shear heads. The system uses headed shear studs installed in a conventional manner (perpendicular to the slab plane) combined with a second family of large-diameter shear studs arranged horizontally in the compression side of the slab (parallel to the slab plane) to activate them as dowel reinforcement (refer to Fig. 2). The idea grounding this innovative punching reinforcement solution is based on the capacity of the reinforcement in the compression side of the slab to efficiently transfer shear forces as a dowel. This capacity, demonstrated experimentally in many cases for the integrity reinforcement during the post-punching behavior of flat slabs, ${ }^{6-8}$ has also been shown to be a potential contribution for beams in shear. ${ }^{9,10}$ In this paper, the results of a test program on 11 slab specimens are presented, comparing the performance in terms of strength and deformation capacity of slab-column connections without any shear reinforcement with conventional double-headed studs and with the innovative punching reinforcing system. The tests are performed on full-scale specimens with different mechanical slenderness (distance between load introduction points and axis of the column divided by the effective depth of the slab) so

ACI Structural Journal, V. 116, No. 5, September 2019

MS No. S-2018-421.R1, doi: 10.14359/51716842, received October 24, 2018, and reviewed under Institute publication policies. Copyright (C) 2019, American Concrete Institute. All rights reserved, including the making of copies unless permission is obtained from the copyright proprietors. Pertinent discussion including author's closure, if any, will be published ten months from this journal's date if the discussion is received within four months of the paper's print publication. 


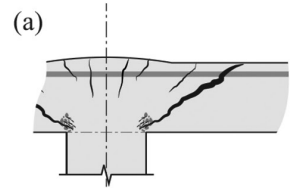

(c)

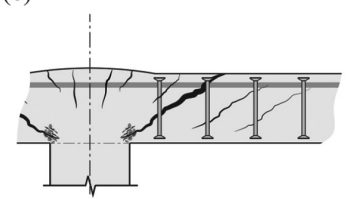

(b)

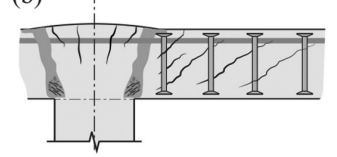

(d)

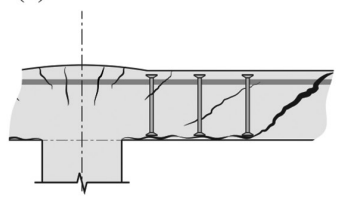

(e)

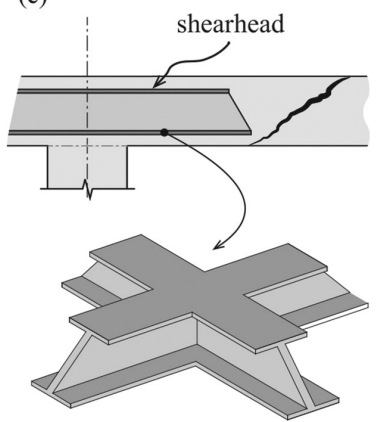

Fig. 1-Punching failures of flat slabs: (a) members without shear reinforcement; (b) crushing of concrete; (c) crack development within shear-reinforced zone; (d) punching outside shear-reinforced zone; and (e) example of steel shear head embedded in slab.
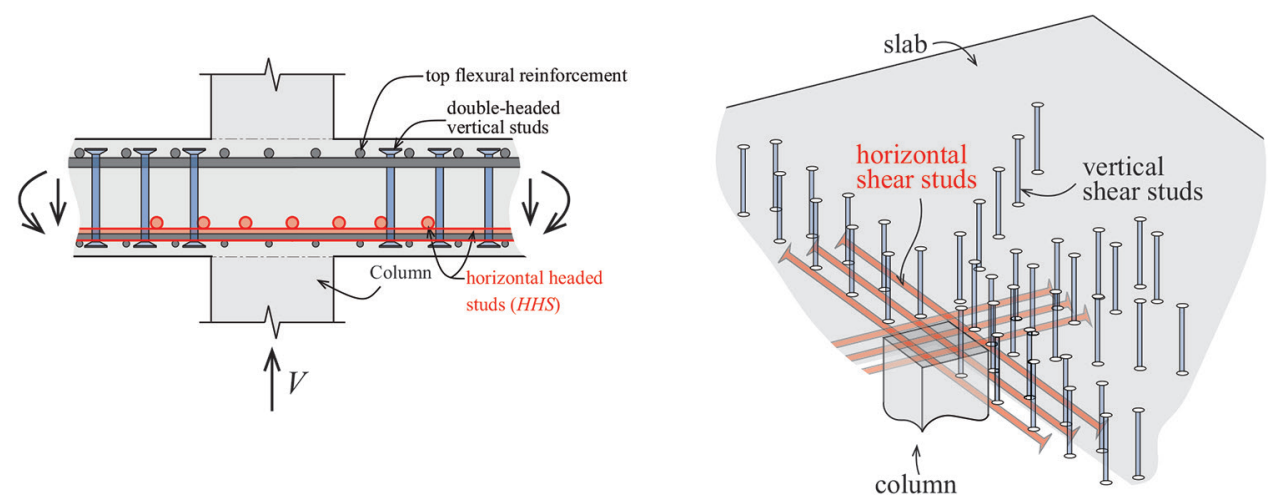

Fig. 2-Arrangement of innovative shear-reinforcing system with horizontal shear studs.

as to investigate various realistic situations. The enhanced performance is demonstrated, as well as the maximum level of strength that can be attained with this system. On that basis, a consistent model for its design is presented based on the Critical Shear Crack Theory (CSCT). To that aim, the mechanical model of this theory ${ }^{11,12}$ is adapted accounting for the contribution of the horizontal studs activated as dowel reinforcement. This approach is shown to predict the strength of the test results in a consistent manner.

\section{RESEARCH SIGNIFICANCE}

Systems to reinforce against punching shear in slabcolumn connections have remained similar in concept since long, by arrangement of a transverse reinforcement anchored in the compression and tension sides of the slab. When their maximum capacity is attained and the geometry of the slab and of column cannot be modified, relatively expensive solutions as embedded shear heads have to be used. In addition, in some cases, an enhancement of the deformation capacity is required (in seismic areas, for instance).

This paper introduces an innovative solution where the arrangement of a shear head is replaced by a number of large-diameter horizontal shear studs in the compression side of the slab. This solution, significantly more competitive from an economic perspective, allows enhancing the performance of shear-reinforced slab-column connections both in terms of their strength and deformation capacity. The system can thus constitute an interesting and economic alternative to conventional punching shear reinforcing solutions.

\section{EXPERIMENTAL PROGRAM}

An experimental program on 11 full-size reinforced concrete slabs was carried out in the Structural Concrete Laboratory of École Polytechnique Fédérale de Lausanne (Switzerland). The experimental program included two reference tests without shear reinforcement (PC23 and PC25), two reference tests with standard double-headed vertical (perpendicular to the slab plane) studs (PC24 and PC26), and seven tests with the innovative solution investigated, combination of standard vertical double-headed bars and largediameter horizontal double-headed bars in the compression face of the slab (PP10 and PP12 to PP17). The geometry of the specimens and loading conditions were also selected to allow direct comparisons to four experimental tests already performed by the authors ${ }^{13}$ (PV1, PL1, PL6, and PL7).

\section{Main parameters and test setup}

All members were square in plan and with a side dimension of $3000 \mathrm{~mm}(9.84 \mathrm{ft})$. The nominal thickness was also constant for all tests and equal to $250 \mathrm{~mm}$ (9.84 in.).

Loads were introduced at eight points (refer to Fig. 3) by means of four hydraulic jacks with a total capacity of $4 \mathrm{x}$ 2.5 MN (4 x 562 kip). The jacks transferred their load by means of four $75 \mathrm{~mm}$ (2.95 in.) steel rods to steel spreader beams, supported each on two loading plates $200 \times 200 \times$ $40 \mathrm{~mm}(7.87 \times 7.87 \times 1.57 \mathrm{in}$.). Three different load introduction radii $r_{q}$ (Fig. 4), ranging from 765 to $1505 \mathrm{~mm}$ (2.51 to $4.94 \mathrm{ft}$ ), were investigated (refer to Table 1) representing slab slenderness $L / d$ between 16 and 32 (refer to Fig. 4(a)). This variation allowed investigation on the response of the 
slab-column connections for rather slender to rather squat flat slabs. The slab was finally supported on a central steel column of variable dimensions (refer to Fig. 4(a) and Table 1). A thin layer of plaster was placed between the steel column and the slab to allow for a distributed load introduction.

All slabs were cast with normal-strength concrete whose compressive strength at the day of testing ranged between 24.9 and $37.0 \mathrm{MPa}$ (3.61 and $5.37 \mathrm{ksi}$ ), (average of three compressive tests on $160 \times 320 \mathrm{~mm}$ [6.3 x 12.6 in.] concrete cylinders); refer to the details in Table 1 . The maximum aggregate size was $16 \mathrm{~mm}$ (0.63 in.) for all test specimens.

The flexural reinforcement consisted of hot-rolled $\left(d_{b}=\right.$ $20 \mathrm{~mm}$ [0.78 in.]) reinforcing bars with a well-defined yield plateau for the top (tension) side spaced at $100 \mathrm{~mm}$ (3.94 in.). The nominal effective depth $\left(d_{\text {nom }}=210 \mathrm{~mm}[8.27 \mathrm{in}].\right)$ and the flexural reinforcement ratio $\left(\rho_{l}=1.50 \%\right)$ were kept constant for all specimens. This reinforcement amount was selected to have a large flexural capacity and to promote

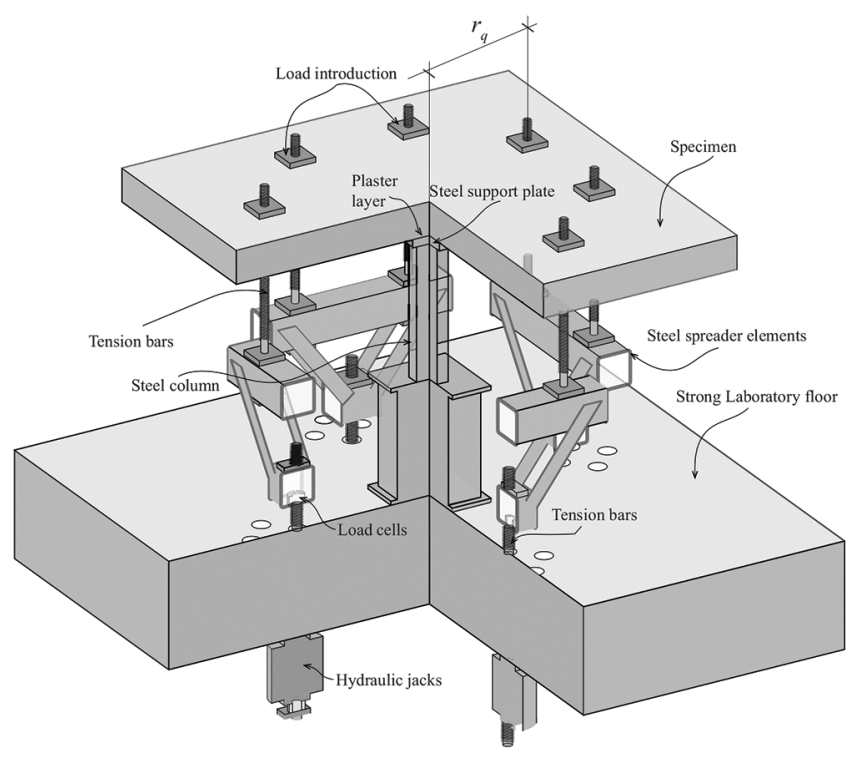

Fig. 3-View of test setup. failures in punching shear. ${ }^{11}$ After testing, specimens were saw-cut and the actual effective depth was measured; refer to Table 1 for details. Cold-worked $\left(d_{b}=14 \mathrm{~mm}\right.$ [0.55 in.]) bars (without a clear yield plateau) were used on the bottom (compression) side with a constant spacing of $100 \mathrm{~mm}$ (3.94 in.).

For all slabs with shear reinforcement (refer to Fig. 4(b)), double-headed vertical studs were arranged following a quasi-radial layout (refer to material details in Table 2). The nominal radial distance between the column edge and the first stud was $s_{0}=80 \mathrm{~mm}$ (3.15 in.), while the radial distance between consecutive studs $s_{1}$ ranged between 105 and $160 \mathrm{~mm}$ (4.13 and $5.91 \mathrm{in}$.) (refer to the details in Table 2). The amount of shear reinforcement $\rho_{w}$ (refer to the definition in Table 1) varied between $0.93 \%$ and $1.08 \%$ (refer to the details in Table 1) and was selected to attain the maximum punching resistance due to crushing of concrete between the column edge and the first perimeter of shear reinforcement. ${ }^{13}$ To fix the position of the vertical double-headed shear studs, $5 \times 40 \mathrm{~mm}(0.19 \times 0.78$ in.) thin steel plates were welded to the bottom head of the shear studs. Details on the number of radii, studs per radius, and yield strength can be found in Table 2 for each specimen. The nominal concrete cover of the studs $c_{\text {nom }}=20 \mathrm{~mm}$ (0.79 in.) was kept constant for all specimens.

\section{Horizontal studs}

In addition to the conventional vertical shear studs, seven slabs (named PP) were equipped with additional doubleheaded studs installed horizontally (refer to Fig. 5(a)). The horizontal studs were aimed to act as shear dowels with the anchorage heads located outside of the punching failure region. ${ }^{7}$ The choice of horizontal studs allows for relatively short bar dimensions so as to allow preassembling the horizontal and vertical studs and ease placement during construction. The properties, head dimensions, and mechanical performance of this additional longitudinal reinforcement were the same as that of vertical shear studs (steel class B500B

(a)

(b)
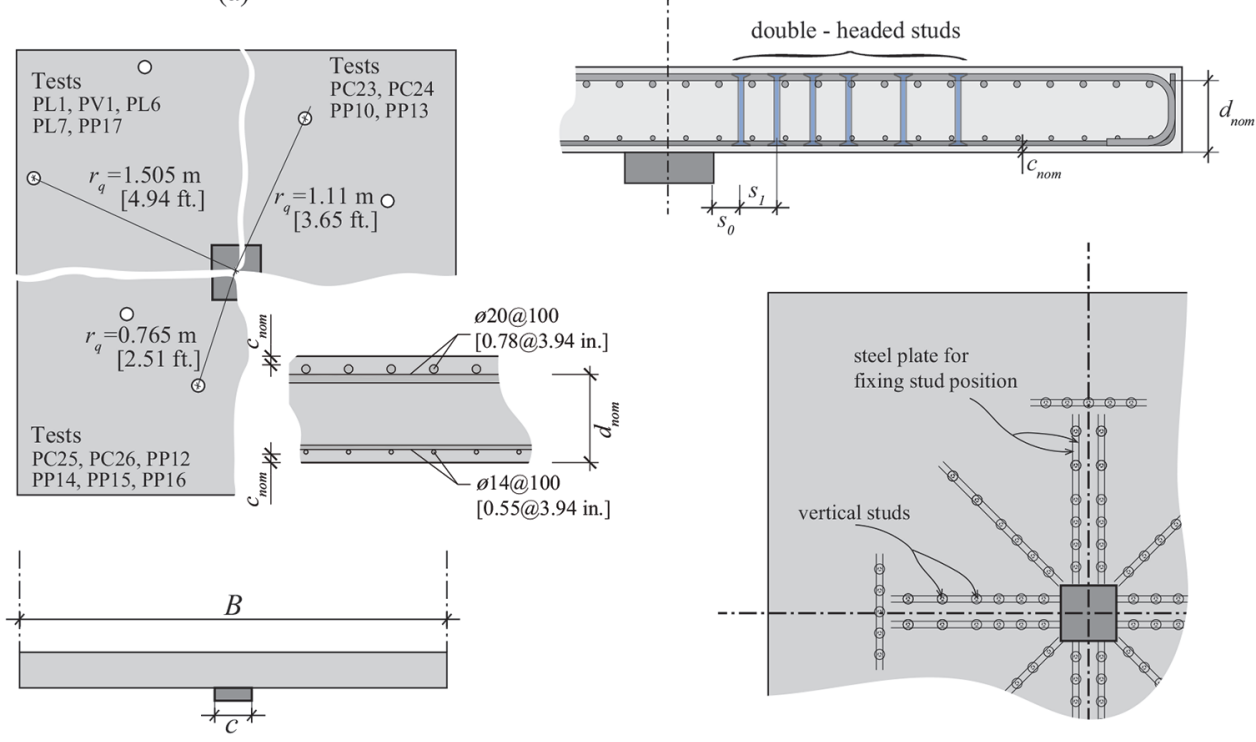

Fig. 4-Test specimens: (a) geometric parameters; and (b) arrangement of double-headed studs. 
Table 1-Main parameters of test series

\begin{tabular}{c|c|c|c|c|c|c|c|c}
\hline Slab & $B, \mathrm{~m}(\mathrm{ft})$ & $c, \mathrm{~mm}(\mathrm{in})$. & $r_{q}, \mathrm{~m}(\mathrm{ft})$ & $d, \mathrm{~mm}(\mathrm{in})$. & $f_{y}, \mathrm{MPa}(\mathrm{ksi})$ & $f_{c}, \mathrm{MPa}(\mathrm{psi})$ & $\rho_{b}, \%$ & $\rho_{w}{ }^{*}, \%$ \\
\hline PL1 & $3.0(9.84)$ & $130(5.12)$ & $1.505(4.94)$ & $193(7.60)$ & $583(84.6)$ & $36.2(5250)$ & 1.63 & - \\
\hline PV1 & $3.0(9.84)$ & $260(10.2)$ & $1.505(4.94)$ & $210(8.27)$ & $709(102)$ & $34.0(4900)$ & 1.50 & 1.59 \\
\hline PL6 & $3.0(9.84)$ & $130(5.12)$ & $1.505(4.94)$ & $198(7.79)$ & $583(84.6)$ & $36.6(5300)$ & 1.01 \\
\hline PL7 & $3.0(9.84)$ & $260(10.2)$ & $1.505(4.94)$ & $197(7.76)$ & $519(75.3)$ & $35.9(5200)$ & 1.59 & 0.93 \\
\hline PC23 & $3.0(9.84)$ & $260(10.2)$ & $1.11(3.65)$ & $212(8.34)$ & $570(82.7)$ & $34.6(5020)$ & 1.48 & 1.50 \\
\hline PC24 & $3.0(9.84)$ & $260(10.2)$ & $1.11(3.65)$ & $209(8.22)$ & $570(82.7)$ & $37.0(5370)$ & 1.07 \\
\hline PC25 & $3.0(9.84)$ & $260(10.2)$ & $0.765(2.51)$ & $203(7.99)$ & $586(85.0)$ & $34.8(5050)$ & 1.55 & - \\
\hline PC26 & $3.0(9.84)$ & $260(10.2)$ & $0.765(2.51)$ & $204(8.03)$ & $586(85.0)$ & $31.9(4630)$ & 1.54 & 1.08 \\
\hline PP10 & $3.0(9.84)$ & $260(10.2)$ & $1.11(3.65)$ & $207(8.15)$ & $570(82.7)$ & $24.9(3610)$ & 1.52 & 0.92 \\
\hline PP12 & $3.0(9.84)$ & $260(10.2)$ & $0.765(2.51)$ & $212(8.35)$ & $569(82.5)$ & $29.7(4300)$ & 1.48 & 1.07 \\
\hline PP13 & $3.0(9.84)$ & $260(10.2)$ & $1.11(3.65)$ & $208(8.19)$ & $569(82.5)$ & $27.8(4030)$ & 1.51 & 1.07 \\
\hline PP14 & $3.0(9.84)$ & $260(10.2)$ & $0.765(2.51)$ & $214(8.43)$ & $557(80.8)$ & $34.9(5060)$ & 1.47 & 1.06 \\
\hline PP15 & $3.0(9.84)$ & $260(10.2)$ & $0.765(2.51)$ & $206(8.11)$ & $570(82.7)$ & $28.1(4080)$ & 1.53 & 1.08 \\
\hline PP16 & $3.0(9.84)$ & $260(10.2)$ & $0.765(2.51)$ & $213(8.39)$ & $557(80.8)$ & $35.0(5080)$ & 1.47 & 1.06 \\
\hline PP17 & $3.0(9.84)$ & $130(5.12)$ & $1.505(4.94)$ & $206(8.11)$ & $570(82.7)$ & $29.4(4260)$ & 1.52 & 1.56 \\
\hline
\end{tabular}

${ }^{*} \rho_{w}$ is defined by considering reference perimeter at $0.5 d_{n o m}$ from edge of column according to following equation: $\rho_{w}=A_{s w, i} \cdot n_{r} / u \cdot s$, where $u$ is length of perimeter at distance $0.5 d_{n o m}$ from edge of column; $A_{s w, i}$ is cross-sectional area of double-headed stud; and $s=s_{0}+s_{1} / 2$.

\section{Table 2-Main parameters of shear studs}

\begin{tabular}{|c|c|c|c|c|c|c|}
\hline Slab & $d_{b}, \mathrm{~mm}$ (in.) & $n_{r}$ & $n_{s}$ & $s_{0}, \mathrm{~mm}$ (in.) & $s_{1}, \mathrm{~mm}$ (in.) & $f_{y}, \mathrm{MPa}(\mathrm{ksi})$ \\
\hline PL6 & $14(0.55)$ & 12 & 6 & $80.0(3.15)$ & $160(6.30)$ & $519(75.3)$ \\
\hline PL7 & $14(0.55)$ & 16 & 7 & $80.0(3.15)$ & $160(6.30)$ & $536(77.7)$ \\
\hline PC26 & $16(0.63)$ & 12 & 5 & $80.0(3.15)$ & $105(4.13)$ & - \\
\hline PP10 & $16(0.63)$ & 12 & 6 & $80.0(3.15)$ & $150(5.91)$ & - \\
\hline PP13 & $16(0.63)$ & 12 & 6 & $80.0(3.15)$ & $105(4.13)$ & $559(81.1)$ \\
\hline PP14 & $16(0.63)$ & 12 & 5 & $80.0(3.15)$ & $105(4.13)$ & $557(80.8)$ \\
\hline PP15 & $16(0.63)$ & 12 & 5 & $80.0(3.15)$ & $105(4.13)$ & $555(80.5)$ \\
\hline PP16 & $16(0.63)$ & 12 & 5 & $80.0(3.15)$ & $105(4.13)$ & $557(80.8)$ \\
\hline
\end{tabular}

according to EN $10080^{14}$ ) and can be consulted in Table 2. These bars had a total length of $1200 \mathrm{~mm}(3.94 \mathrm{ft})$ and were arranged with a constant spacing ranging between 80 and $100 \mathrm{~mm}$ (3.15 and $3.94 \mathrm{in}$.). The length of the horizontal studs was selected to locate the heads of the bars outside of the punching region. Details on the layout of these bars can be found in Fig. 5(c) and Table 3, together with the location of the center of gravity of these horizontal studs represented by parameter $c_{d}$ (defined in Fig. 5(a)), which represents the distance of the interface between the two layers of horizontal studs with respect to the compression side.

Three of these slabs (PP10, PP12, and PP14) were also reinforced with additional horizontal double-headed studs on the tension side; refer to Fig. 5(b) and Table 4. This additional reinforcement was arranged to investigate their effect on the load-carrying capacity (studs acting predominantly as dowel and/or flexural reinforcement). In Table 4, when these bars are arranged, the flexural reinforcement amount is increased accordingly.

\section{Test results}

The measured load-rotation curves (the self-weight of the specimens is included in the resultant shear force) are presented in Fig. 6 (both for the 11 specimens tested in this program and for the four additional reference specimens tested on other series but with the same geometric, loading, and mechanical properties ${ }^{13}$ ). The rotation $\psi$, refer to Fig. 6(a), was measured by means of four inclinometers arranged along the two symmetry axes of the slab and approximately at the point of moment contraflexure (according to a linear-elastic calculation). The average of the four measured rotations was finally represented for the evaluation of the overall flexural behavior (Fig. 6). The saw-cuts of the specimens after testing are also presented in Fig. 7. 
Failures for most tests occurred by punching at the slabcolumn connection prior to reaching the full development of a flexural mechanism. For one specimen (PP13), failure was controlled by bending, as delamination of the concrete cover in the compression face occurred, thus reducing the effective depth of the section. A similar failure mode controlled by delamination was also observed for specimen PP10, although a conical punching surface eventually developed (as can be seen in the saw-cut of Fig. 7).

\section{Table 3-Layout of shear reinforcing system}

\begin{tabular}{|c|c|c|c|c|}
\hline Slab & Description & $\begin{array}{l}s_{1}, \mathrm{~mm} \\
\quad \text { (in.) }\end{array}$ & $\begin{array}{c}s_{H H S} \\
\mathrm{~mm} \text { (in.) }\end{array}$ & $\begin{array}{l}c_{d}, \mathrm{~mm} \\
\quad \text { (in.) }\end{array}$ \\
\hline PL6 & Vertical shear studs (VSS) & $\begin{array}{c}160 \\
(6.30)\end{array}$ & - & - \\
\hline PL7 & $V S S$ & $\begin{array}{c}160 \\
(6.30)\end{array}$ & - & - \\
\hline $\mathrm{PC} 24$ & $V S S$ & $\begin{array}{c}105 \\
(4.13)\end{array}$ & - & - \\
\hline $\mathrm{PC} 26$ & $V S S$ & $\begin{array}{c}105 \\
(4.13)\end{array}$ & - & - \\
\hline PP10 & $\begin{array}{l}\text { VSS and HHS bars } \\
\text { (top and bottom side) }\end{array}$ & $\begin{array}{c}150 \\
(5.91)\end{array}$ & $\begin{array}{c}100 \\
(3.94)\end{array}$ & $\begin{array}{c}73.0 \\
(2.87)\end{array}$ \\
\hline PP12 & $\begin{array}{l}\text { VSS and HHS bars } \\
\text { (top and bottom side) }\end{array}$ & $\begin{array}{c}105 \\
(4.13)\end{array}$ & $\begin{array}{c}100 \\
(3.94)\end{array}$ & $\begin{array}{l}59.0 \\
(2.32)\end{array}$ \\
\hline PP13 & $\begin{array}{l}V S S \text { and } H H S \text { bars } \\
\text { (bottom side) }\end{array}$ & $\begin{array}{c}105 \\
(4.13)\end{array}$ & $\begin{array}{c}100 \\
(3.94)\end{array}$ & $\begin{array}{l}59.0 \\
(2.32)\end{array}$ \\
\hline PP14 & $\begin{array}{l}\text { VSS and HHS bars } \\
\text { (top and bottom side) }\end{array}$ & $\begin{array}{c}105 \\
(4.13)\end{array}$ & $\begin{array}{c}100 \\
(3.94)\end{array}$ & $\begin{array}{c}66.0 \\
(2.60)\end{array}$ \\
\hline PP15 & $\begin{array}{l}V S S \text { and } H H S \text { bars } \\
\text { (bottom side) }\end{array}$ & $\begin{array}{c}105 \\
(4.13)\end{array}$ & $\begin{array}{c}100 \\
(3.94)\end{array}$ & $\begin{array}{l}74.0 \\
(2.91)\end{array}$ \\
\hline PP16 & $\begin{array}{l}V S S \text { and } H H S \text { bars } \\
\text { (bottom side) }\end{array}$ & $\begin{array}{c}105 \\
(4.13)\end{array}$ & $\begin{array}{c}100 \\
(3.94)\end{array}$ & $\begin{array}{c}66.0 \\
(2.60)\end{array}$ \\
\hline PP17 & $\begin{array}{l}V S S \text { and } H H S \text { bars } \\
\text { (bottom side) }\end{array}$ & $\begin{array}{c}105 \\
(4.13)\end{array}$ & $\begin{array}{c}80 \\
(3.15)\end{array}$ & $\begin{array}{c}66.0 \\
(2.60)\end{array}$ \\
\hline
\end{tabular}

(a)

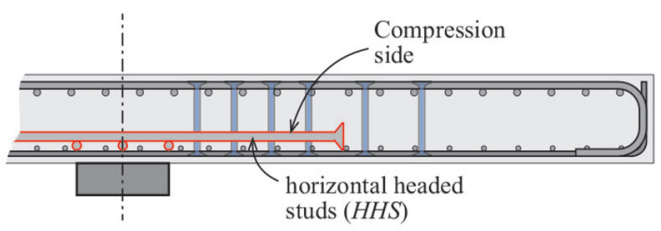

(c)
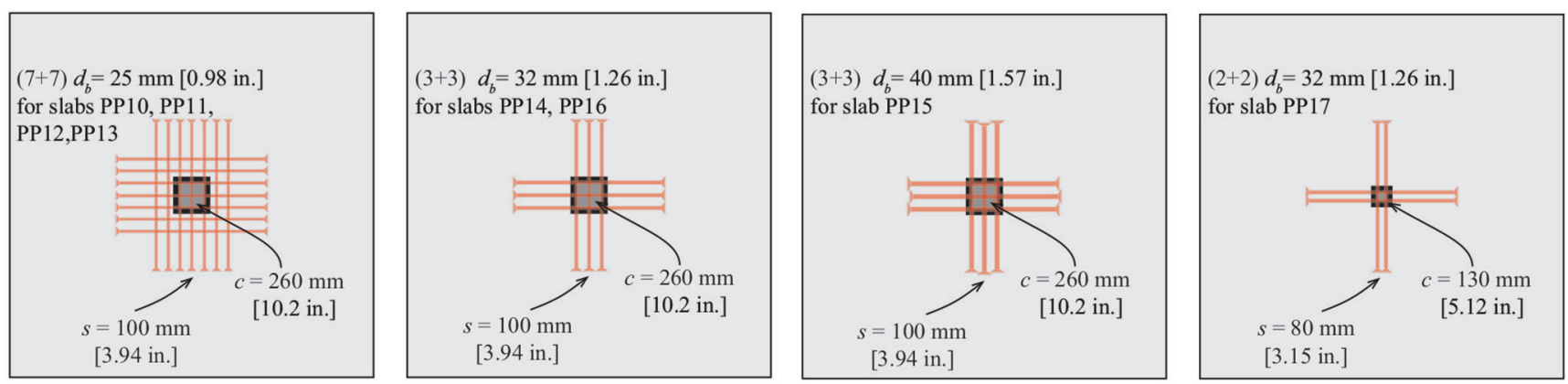

Fig. 5-Shear dowels: (a) shear reinforcing system arrangement in bottom (compression) side; (b) shear reinforcing system arrangement in bottom (compression) and top (tension) side; and (c) amount of reinforcing bars, spacing, and reinforcing bar diameter for each specimen. 
Table 4-Main parameters of shear reinforcing system

\begin{tabular}{c|c|c|c|c|c|c}
\hline Slab & $d_{b-H H S}, \mathrm{~mm}(\mathrm{in})$. & $f_{y}, \mathrm{MPa}(\mathrm{ksi})$ & $f_{t}, \mathrm{MPa}(\mathrm{ksi})$ & $H H S$ bottom side & $H H S$ top side & $d_{\text {avg, }} \mathrm{mm}(\mathrm{in} .)^{*}$ \\
\hline PP10 & $25(0.98)$ & $578(83.8)$ & $680(98.6)$ & $7+7$ bars & $7+7$ bars & $195(7.7)$ \\
\hline PP12 & $25(0.98)$ & $529(76.7)$ & $609(88.3)$ & $7+7$ bars & $7+7$ bars & $200(7.9)$ \\
\hline PP13 & $25(0.98)$ & $529(76.7)$ & $607(88.0)$ & $7+7$ bars & - \\
\hline PP14 & $32(1.26)$ & $534(77.5)$ & $629(92.7)$ & $3+3$ bars & $3+3$ bars & $203(8.0)$ \\
\hline PP15 & $40(1.57)$ & $576(83.5)$ & $690(100)$ & $3+3$ bars & - \\
\hline PP16 & $32(1.26)$ & $534(77.5)$ & $629(92.7)$ & $3+3$ bars & - \\
\hline PP17 & $32(1.26)$ & $504(73.1)$ & $623(90.4)$ & $2+2$ bars & - \\
\hline
\end{tabular}

${ }^{*} d_{\text {avg }}$ is nominal distance from extreme compression fiber to centroid of longitudinal tensile reinforcement in case of horizontal headed studs positioned in tensile zone.

(a)

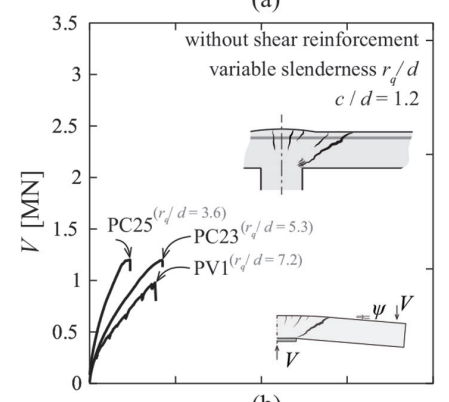

(b)

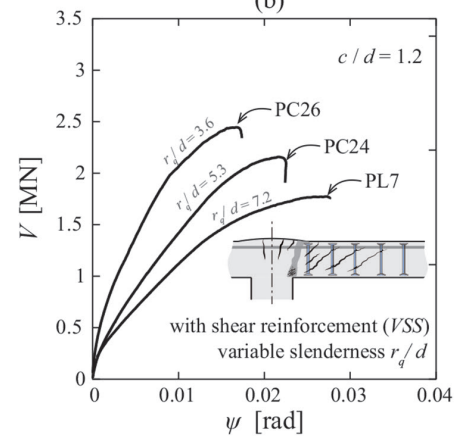

(c)

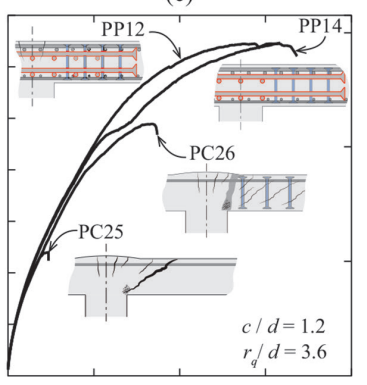

(d)

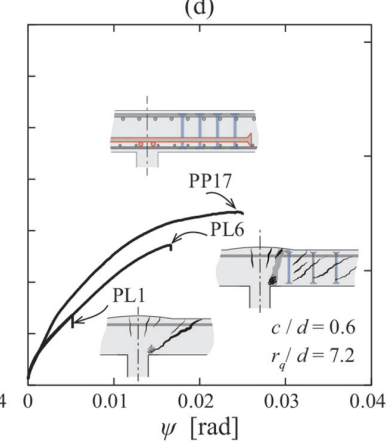

(e)

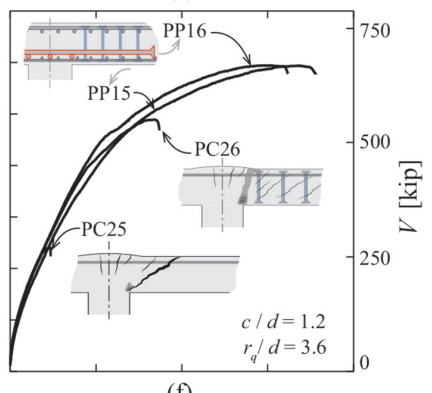

(f)

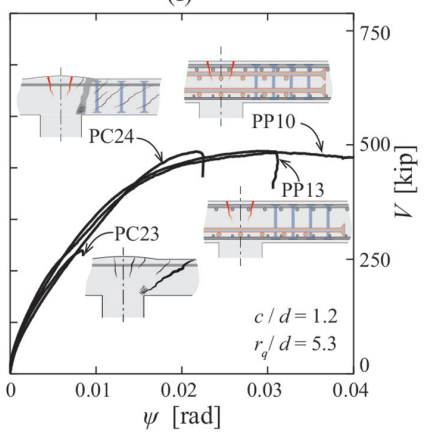

Fig. 6-Load-rotation curves of specimens: (a) without shear reinforcement and variable slenderness; (b) with shear reinforcement and variable slenderness; (c) column size-slab depth ratio $\mathrm{c} / \mathrm{d}=1.2$ and slab slenderness $\mathrm{r}_{\mathrm{q}} / \mathrm{d}=3.6$; (d) column size-slab depth ratio $\mathrm{c} / \mathrm{d}=0.6$ and slab slenderness $\mathrm{r}_{\mathrm{q}} / \mathrm{d}=7.2 ;$ (e) column size-slab depth ratio $\mathrm{c} / \mathrm{d}=1.2$ and slab slenderness $\mathrm{r}_{\mathrm{q}} / \mathrm{d}=3.6$; and $(f)$ column size-slab depth ratio $\mathrm{c} / \mathrm{d}=1.2$ and slab slenderness $\mathrm{r}_{\mathrm{q}} / \mathrm{d}=5.3$.

with respect to specimens without shear reinforcement or reinforced with conventional vertical studs only. In Fig. 6(c) through (e), the results for the specimens with lower mechanical slenderness $\left(r_{q} / d=3.6\right)$ are presented. A significant increase for the specimens with horizontal dowel studs is observed in terms of failure load (up to 250 to $270 \%$ of the failure load observed in the members without shear reinforcement) and of the deformation capacity (up to $700 \%$ of the value of specimens without shear reinforcement).

For the specimens with the highest mechanical slenderness and lowest column dimension $\left(r_{q} / d=7.2\right.$; refer to Fig. $6(\mathrm{~d})$ and Fig. 8), the system showed a similar behavior with an enhanced performance both in terms of resistance and deformation capacity. For the tests with intermediate slenderness $\left(r_{q} / d=5.3\right.$; refer to Fig. 6(f) ), the resistance of the connection was increased when the influence of the compressive strength of concrete is accounted for (Fig. 8). The deformation capacity was in any case notably increased.

\section{Activation of horizontal dowels}

The enhanced performance of the specimens reinforced with the horizontal headed bars is justified by their activation as shear dowels, allowing to transfer a fraction of the total shear force. To investigate this phenomenon in detail, specific measurements were performed on these bars by means of strain gauges. Figures 9(a) and (b) show the location of these gauges glued on the top and bottom surface of the bars.

The experimental results for Specimen PP12 are shown in Fig. 9(c) through (e). It can be noted that the gauges on the bottom side near the column were in compression while the gauges on the top side were in tension. Close to failure, significant plastic deformations were recorded in the bar near the column region as observed from the profiles of curvatures measured in Fig. 9(c). The opposite occurred for the gauges glued at a certain distance of the column, with tension on the bottom side and compression on the top side (the recorded strains being yet lower). These measurements clearly correspond to the expected profile for a doweled bar 


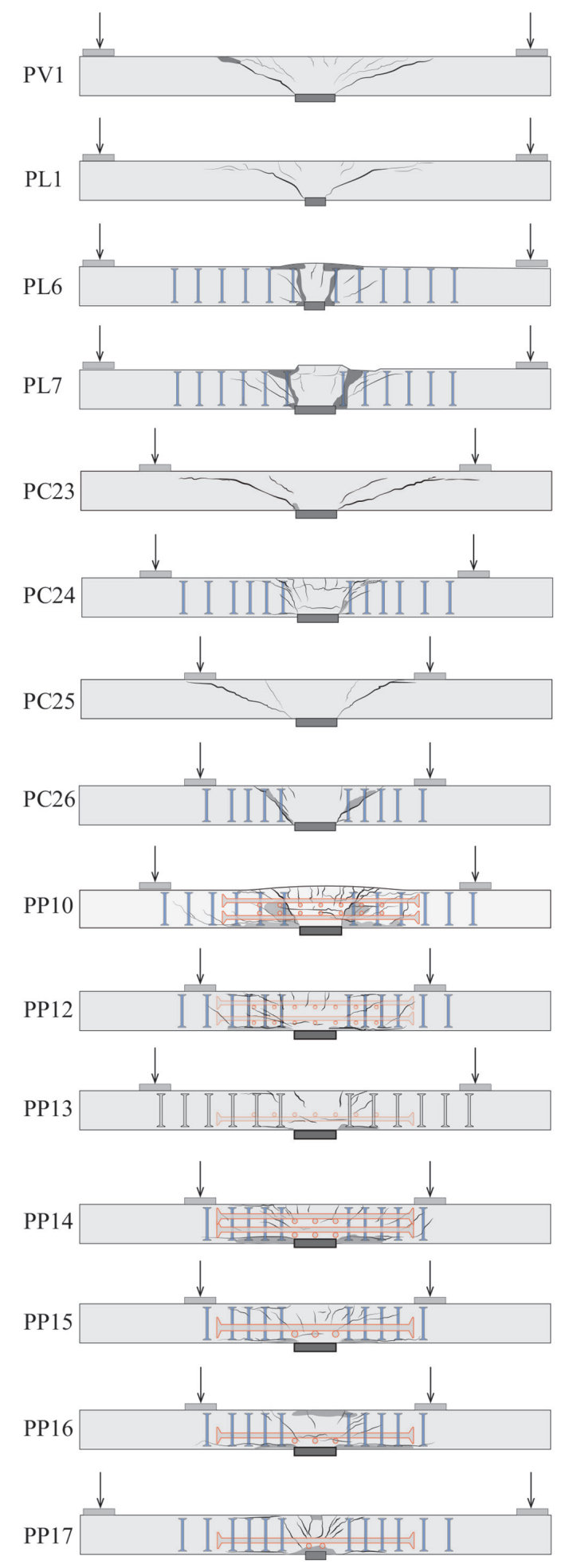

Fig. 7-Saw-cuts of slabs along weak axis.

with a point of contraflexure (refer to Fig. 9(c)). It can be noted that the activation of the doweling action was observed even for low levels of load, approximately $20 \%$ of the failure load, which corresponds to approximately $80 \%$ of the failure of the reference specimen without transverse reinforcement. This indicates that the doweling action is already activated by the development of the inclined critical shear crack and increases during the test.

The activation of the doweling action of the bars seems, however, to lead to an enhanced potential delamination of
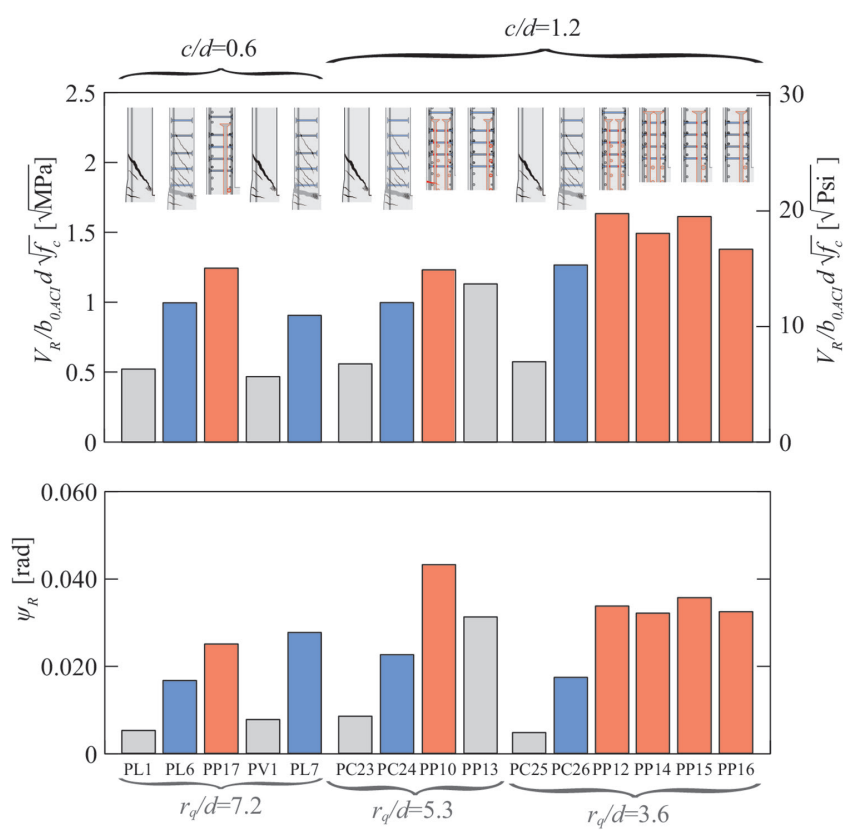

Fig. 8-Comparison of test results: (a) punching strength; and (b) deformation capacity $\psi_{\mathrm{R}}$ at maximum load.

the concrete cover (refer to Fig. 10). During the tests, such delamination cracks were observed in Specimens PP10 and PP13 at approximately $70 \%$ of the failure load. In general, specimens that for a given level of shear force are subjected to larger bending moments were more prone to develop such delamination failures. This was the case of Specimens PP10 and PP13, where the column size was large and the mechanical slenderness was relatively high $\left(r_{q} / d=5.3\right)$ and thus large bending moments developed. For the most slender slabs $\left(r_{q} / d=7.2\right)$, the column was relatively small and the bending moments were thus moderate for the same level of shear force (and delamination was not governing). For the most squat members $\left(r_{q} / d=3.6\right)$, the bending moments were relatively low, thus minimizing such risk.

With respect to the horizontal studs at the (top) tension side of the slab, they contribute as flexural reinforcement, enhancing the flexural stiffness of the slab, and also contribute carrying shear due to doweling action. The former effect (enhancement of flexural stiffness) is directly considered in the load-rotation curve of the specimen, while the latter (doweling contribution) is implicitly considered in the failure criterion. ${ }^{16}$ The pertinence of this consideration is confirmed by the analysis of the three tests conducted with additional horizontal studs in the tension side (presented in the next section).

\section{DESIGN FOR PUNCHING OF SLAB- COLUMN CONNECTIONS ACCOUNTING FOR DOWELING ACTION}

According to the experimental results, the bottom horizontal shear studs were carrying a significant fraction of the shear force, enhancing both strength and deformation capacity of the connections. This contribution can be consistently considered in combination with the other potential shear-transfer actions of concrete ${ }^{16}$ and of the transverse steel. ${ }^{12}$ To that aim, the theoretical framework of the CSCT will be used in the following. 


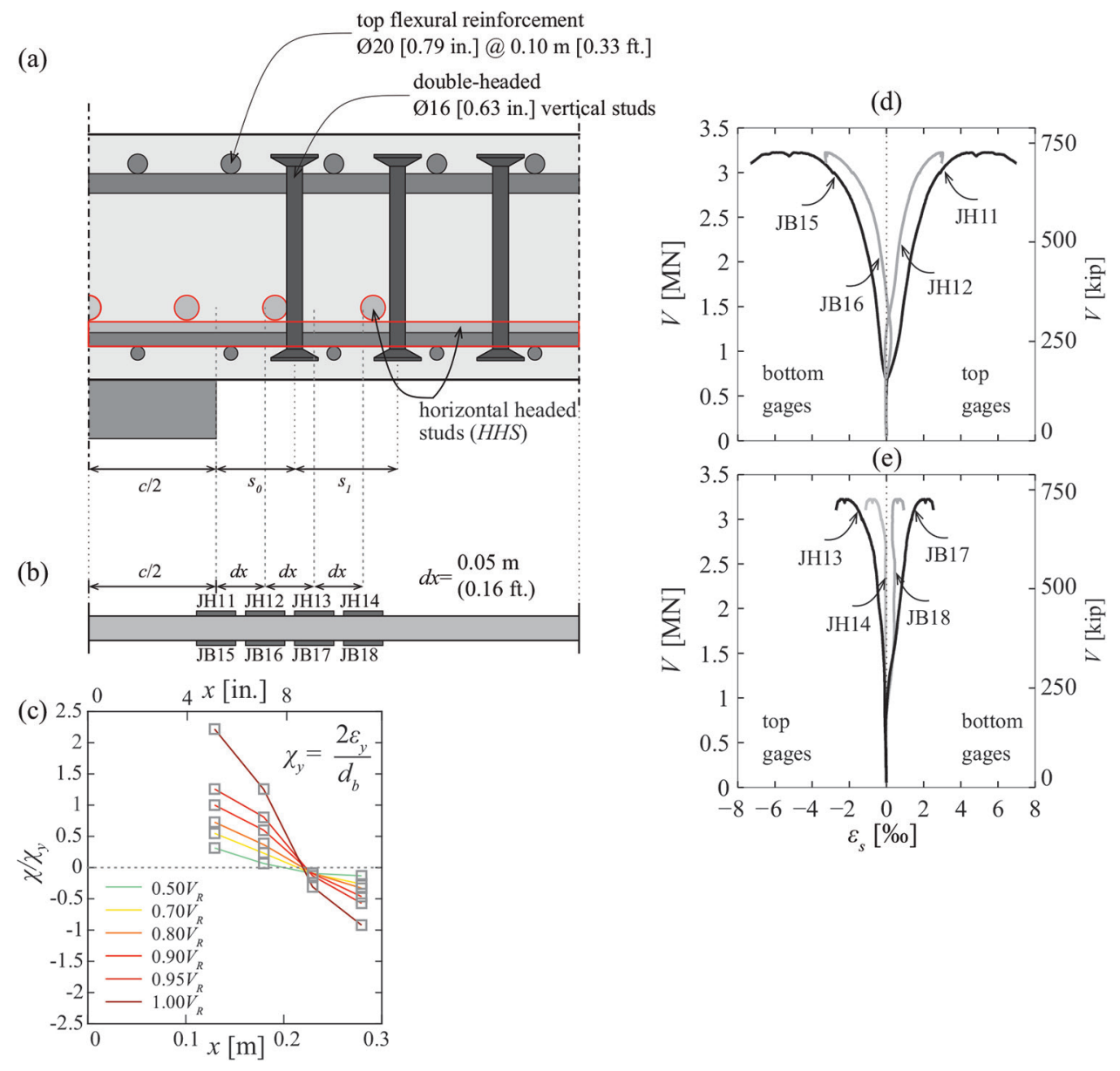

Fig. 9-Activation of dowel reinforcement for test PP12: (a) location of HHS bar where strain measurements were performed (in red); (b) location of strain measurements; (c) curvature profiles along shear dowel; (d) load-steel strains curves of gauges placed on top of investigated bar; and (e) load-steel strains curves of gauges placed on bottom of investigated bar.

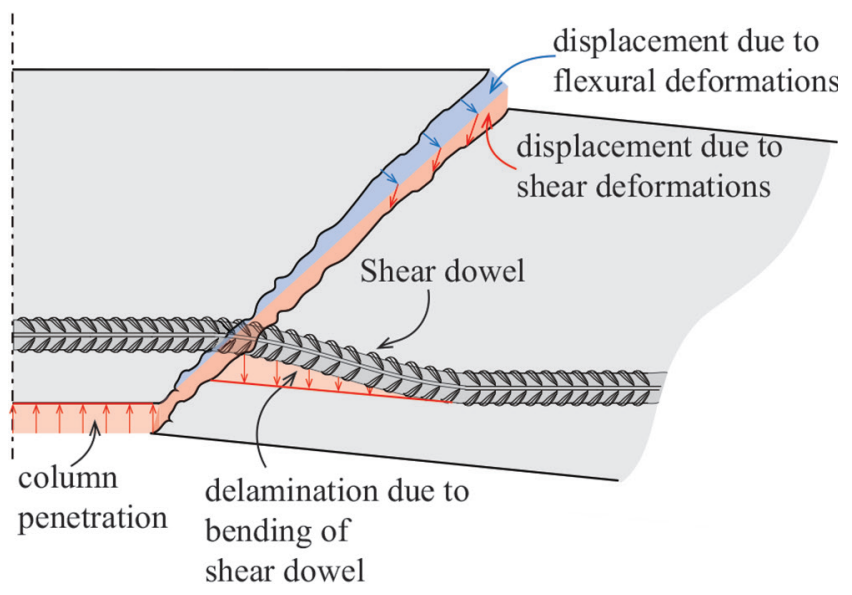

Fig. 10-Doweling of horizontal shear studs and delamination of concrete cover and assumed kinematics according to Simões et al. ${ }^{16}$

\section{Basic assumptions of CSCT}

A complete description of the mechanical model of the CSCT can be found elsewhere. ${ }^{11,12,16}$ For members without transverse reinforcement (Fig. 11(a)), the theory considers that failure is governed by the development of a critical shear crack whose kinematics are defined by two parameters ${ }^{16}$ : the rotation of the slab $\psi$ and the penetration of the failure surface $\delta$. Because at failure both parameters are correlated, ${ }^{16,17}$ the complete mechanical model can be eventually expressed in terms of the rotation of the slab. ${ }^{11}$ The failure load can on this basis be calculated by intersecting the load-rotation response of the slab (defining the shear demand for a given level of deformation) with the failure criterion of concrete (defining the shear resistance for a given level of deformation); refer to Fig. 11(a). According to Muttoni, ${ }^{11}$ a suitable expression for the failure criterion can be adopted as follows (a detailed justification of this expression can be found elsewhere ${ }^{16}$ )

$$
V_{c}=0.75 \frac{\sqrt{f_{c}} \cdot b_{0} \cdot d}{1+15 \frac{\psi \cdot d}{d_{g}+d_{g 0}}}
$$

for SI units ( $\mathrm{m}, \mathrm{MPa}$, and $\mathrm{MN}$ ). For customary units (psi, in., and kip), parameter 0.75 has to be replaced by 9 . The parameter $b_{0}$ refers to the length of a control perimeter located at $d / 2$ from the edge of the column, $d$ to the effective depth of the slab, $d_{g}$ to the maximum aggregate size, and $d_{g 0}$ to a reference aggregate size of $16 \mathrm{~mm}$ (0.63 in.).

When shear reinforcement is arranged, ${ }^{12}$ it is progressively activated by the deformation of the slab; refer to Fig. 11(b). As for the case of members without transverse reinforcement, the 
(a)

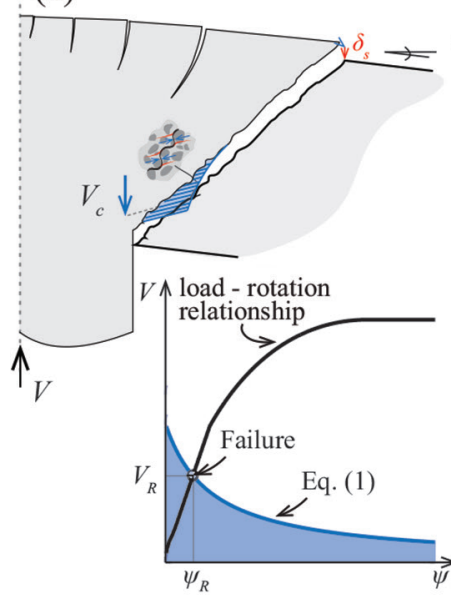

(b)

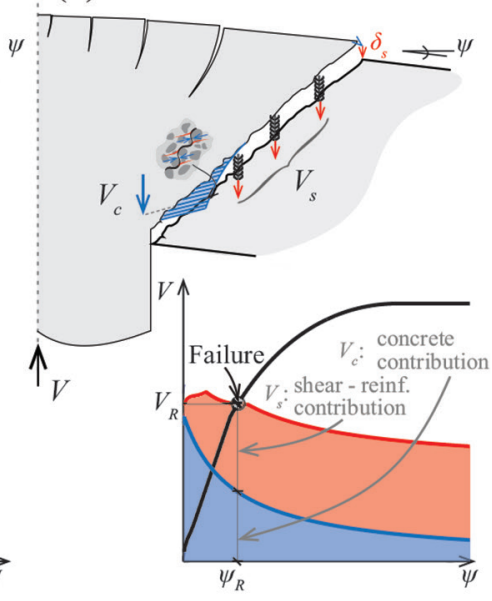

(c)

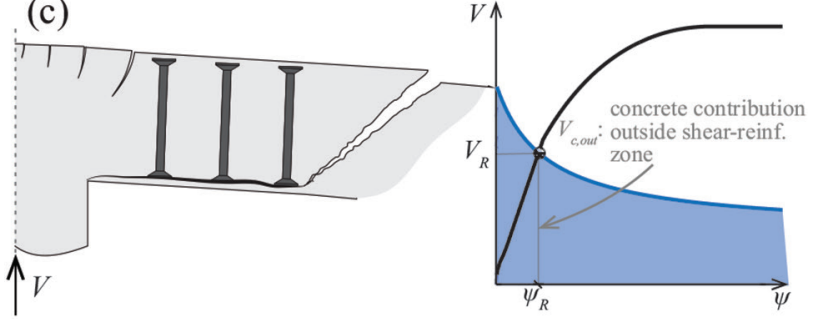

(d)

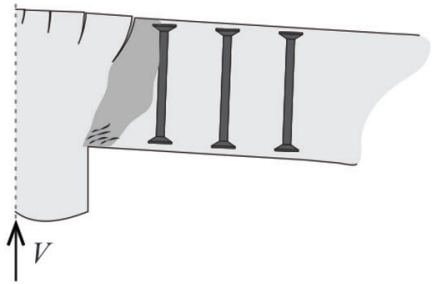

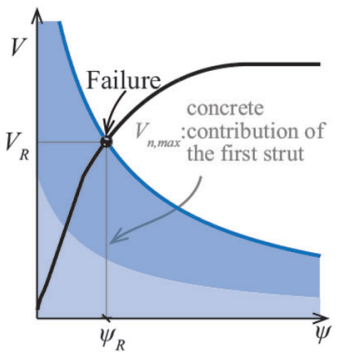

Fig. 11-Shear-carrying actions in slab-column connections: (a) contribution of concrete; (b) contribution of shearreinforcement; (c) contribution of concrete for failures outside shear-reinforced zone; and (d) maximum punching capacity due to crushing of first strut.

failure load can be calculated by intersection of the load-rotation response of the slab and the corresponding failure criterion. In this case, the failure criterion has to also account for the contribution of the transverse reinforcement ${ }^{12}$ (refer to Fig. 11(b))

$$
V_{n}=V_{c}+V_{s}
$$

This reinforcement thus increases both the strength and deformation capacity of the slab-column connection (Fig. 11(b)). Other than by intercepting the transverse reinforcement, failure can occur by punching outside the shear-reinforced area $^{12}$-Fig. 11(c) - or by crushing of the first concrete strut $^{12,13}$ (Fig. 11(d)). For the former of the two, the failure criterion of concrete is considered along a suitable control perimeter located outside of the shear-reinforced area and accounting for a reduced effective depth (considering the location of the anchorage region of the transverse reinforcement). For the latter, the strength of the concrete is normally assessed by multiplying the failure criterion of concrete (Fig. 11(a)) by a suitable factor, whose value depends on the anchorage properties of the shear reinforcement and on its detailing rules ${ }^{5,13,18}$

$$
V_{n, \max }=\lambda V_{c}(\psi)
$$

For the case of vertical shear studs, a typical value ${ }^{19}$ of parameter $\lambda$ is 3.0 , while for stirrups, this value normally reduces to 2.6. It has to be noted that $V_{c}$ depends on rotation $\psi$, which also increases in the case of shear-reinforced slabs. The maximum shear strength $V_{n, \max }$ is thus smaller than $\lambda$ times $V_{c}$ of a slab without shear reinforcement.

\section{Consideration of doweling action on punching shear response}

The model of the CSCT can be extended to shearreinforced slabs by accounting for the contribution of the doweled horizontal bars to carry shear forces. This contri- bution is originated by the penetration of the supported area (Fig. 12(a)), which bends the horizontal bars over the column region (such penetration occurs even for low levels of rotation at failure ${ }^{16}$ ). Figure 13(a) presents the corresponding failure mechanism, which yields to the development of a delamination crack and also to the potential breakout of the concrete anchoring the dowel. On that basis, the failure criterion governed by the maximum punching capacity (governed by crushing of the concrete struts, Eq. (4)) can be expressed as follows

$$
V_{n, \text { max }}=\lambda \cdot V_{c}+\sum V_{d o w}
$$

This equation reflects that a part of the shear force is not carried through the critical shear crack, but directly transferred by the dowelled bars (refer to Fig. 12(a)). The bars contributing to doweling action are assumed to be only those located directly over the supported area, and the total shear force carried by them corresponds to the sum of all sections where the bar is suitably anchored (in the present case, two sections per bar; refer to Fig. 13(c)).

The calculation of the shear force carried by doweling of these bars can be consistently performed accounting for equilibrium and kinematical conditions. This will be presented in the following.

Geometry and kinematics of horizontal shear dowel-The geometrical parameters defining the activation mechanism of the doweled bars are presented in Fig. 13(a). The bar is doweled between two hinges, assumed to reach their plastic condition. Such a plastic state was systematically confirmed by the measurements performed in the bars near the column region (as previously presented) and is assumed as a simplification for the outer hinge. Additionally, the assumed failure mechanism considers the potential presence of a delamination crack (observed in the tests as previously discussed) as well as the potential breakout of the concrete core of the slab. With respect to the breakout cracks, they were also 

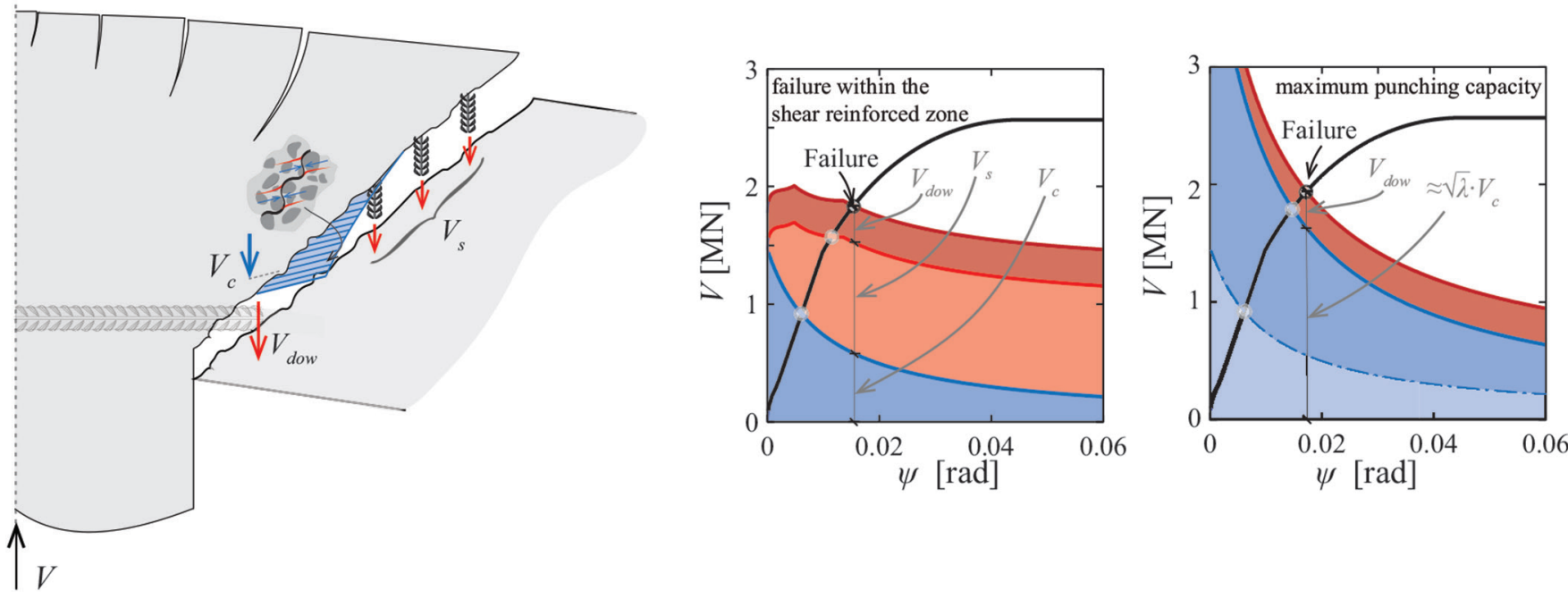

Fig. 12-(a) kinematics of critical shear crack; contributions of shear-carrying mechanisms accounting for activation of shear dowels: (b) punching failure crossing shear-reinforced zone; and (c) maximum punching capacity due to crushing of first compression strut.

clearly observed in the saw-cuts of the specimens; refer, for instance, to Specimens PP10, PP12, or PP16 in Fig. 7.

Capacity of plastic hinges - The capacity of the horizontal bars to transfer shear forces and bending moments is limited by the yield condition of the bar. The interaction between bending moment and shear force is evaluated by considering an equivalent square section. ${ }^{20}$ This equivalent section has a size $b_{e}$, whose value yields the same bending resistance as that of a circular section

$$
M_{R}=d_{b, H H S}^{3} \cdot \frac{f_{y}}{6}=b_{e}^{3} \cdot \frac{f_{y}}{4} \rightarrow b_{e}=d_{b, H H S} \sqrt[3]{2 / 3}
$$

When the section is subjected to a shear force $V_{\text {dow }}$, the required height $h_{\tau}$ to carry the shear force can be calculated assuming a Von Mises yield criterion for steel ${ }^{21}$

$$
h_{\tau}=\frac{V_{d o w}}{b_{e} \cdot f_{y}} \sqrt{3}
$$

Neglecting the axial force, the height of the plastic parts carrying the bending moment is

$$
h_{f}=\frac{b_{e}-h_{\tau}}{2}
$$

In light of this, the plastic strength of the hinges results

$$
M_{R}=b_{e} \cdot h_{f} \cdot f_{y} \cdot\left(b_{e}-h_{f}\right)=\frac{b_{e}^{3}}{4} \cdot f_{y} \cdot\left(1-3 \frac{V_{d d w^{2}}{ }^{2}}{b_{e}^{4} \cdot f_{y}^{2}}\right)=\frac{d_{b, H H S}^{3}}{6} f_{y} \cdot\left(1-5.15 \frac{V_{\text {dow }}{ }^{2}}{d_{b, H H S}^{4} \cdot f_{y}^{2}}\right)
$$

expressing the interaction of the shear and bending capacity for the simplified section of the bar at the yield condition.

Equilibrium conditions of doweled bar-Based on the geometry of the doweled bar (Fig. 13(b)), the equilibrium equation between acting dowel force $\left(V_{d o w}\right)$ and the plastic bending moment $\left(M_{R}\right)$ can be established

$$
M_{R}=V_{d o w} \cdot \frac{l}{2}
$$

where parameter $l$ refers to the distance between plastic hinges (Fig. 13(b)), whose value can be calculated geometrically as

$$
l=c_{d} \cot \alpha+x_{h}+\frac{V_{d o w}}{\phi \cdot f_{c c}}
$$

For the calculation of the length of the plastic hinge (latter term in Eq. (10)), it is estimated, according to Rasmussen, ${ }^{22}$ by assuming a confined concrete strength $f_{c c}=5 f_{c}$ and an effective width equal to the bar diameter. The angle $\alpha$ of the critical shear crack is assumed as 45 degrees according to the test observations on the saw-cuts (Fig. 7). As a result, by combining Eq. (8) and Eq. (9), it results

$$
\frac{d_{b, H H S}^{3}}{6} f_{y} \cdot\left(1-5.15 \frac{V_{d o w}{ }^{2}}{d_{b, H H S}^{4} \cdot f_{y}^{2}}\right)=V_{d o w} \cdot \frac{l}{2}
$$

This expression allows calculating the doweling force that can be transferred by a bar for a given length of the doweled zone.

Concrete breakout conditions - To determine the length for the doweled zone, it has to be considered the maximum capacity of the core to resist the doweling force. This capacity of the concrete is limited by the breakout of the concrete above the outer plastic hinge (Fig. 13(a)). When the capacity of the core is high, large shear forces can be carried and the delamination length is small. On the contrary, when this capacity is low, the delamination length increases and the dowel capacity is limited.

A detailed review of the concrete breakout capacity for such situation can be consulted elsewhere. ${ }^{6,8}$ Most design approaches to this phenomenon propose to calculate this contribution by assuming an effective tensile strength developing at the region of concrete breakout surface. This area 

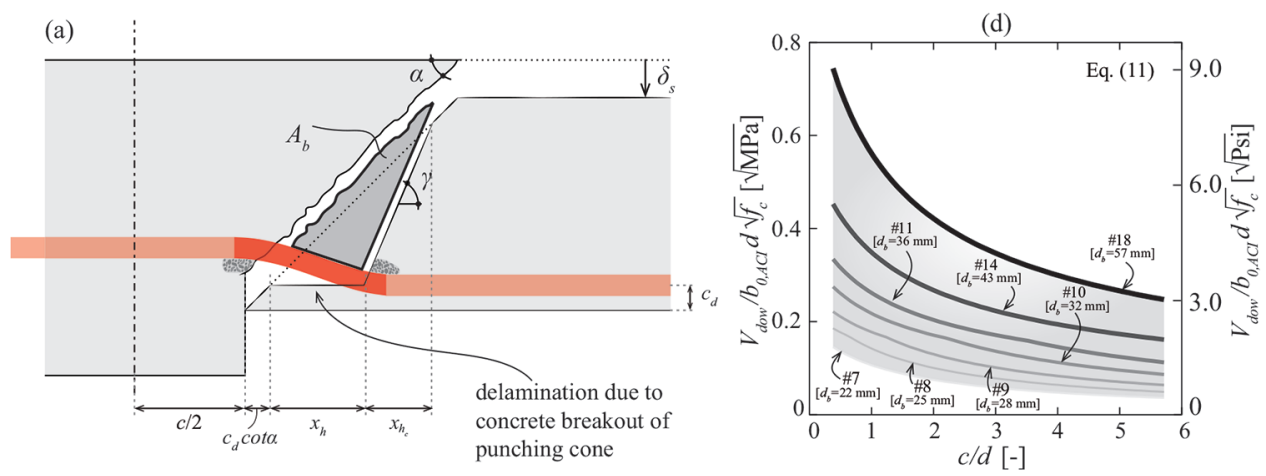

(b)
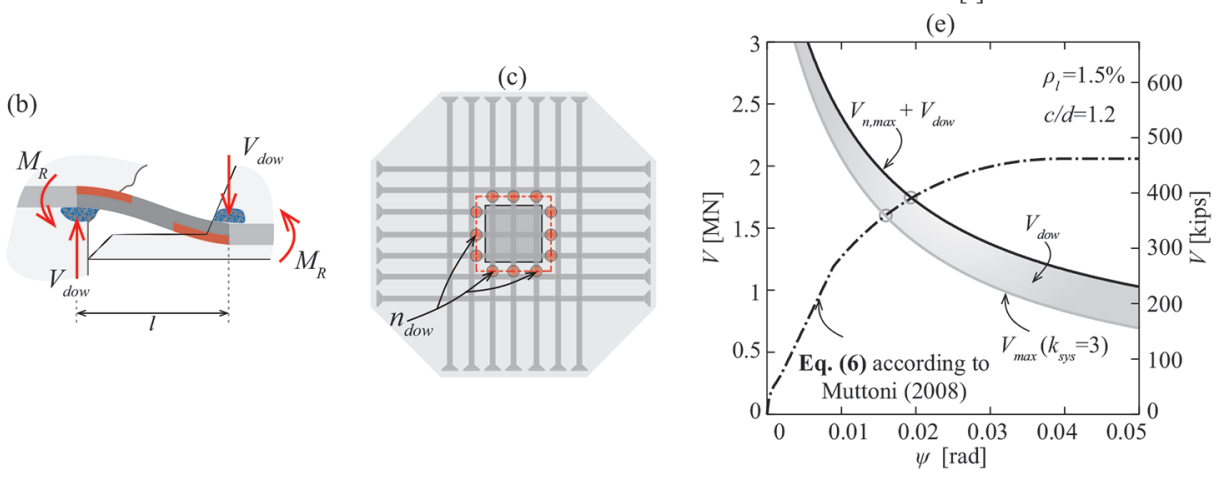

Fig. 13-Assumed failure mechanism and kinematics: (a) parameters; (b) mechanical behavior of dowel; (c) definition of number of intercepted section $\mathrm{n}_{\mathrm{dow}}$; (d) calculated dowel action contribution as function of column size-slab depth ratio; and (e) calculation of failure load by means of quadrilinear law and modified failure criterion.

can be calculated by projecting the concrete breakout surface (assuming an axisymmetric shape). Using the sinus theorem, the distance $x_{h c}$ is equal to

$$
x_{h c}=\min \left(x_{h} \frac{\sin \alpha \cdot \cos \gamma}{\sin (\gamma-\alpha)} ;\left(d-c_{d}\right) \cot \gamma\right)
$$

where $\gamma$ refers to the angle of the concrete breakout surface. To respect the dilatancy of the friction angle of concrete $\varphi$ and to have a vertical shift of the breakout wedge (Fig. 13(a)), the angle $\gamma$ results ${ }^{23}$

$$
\gamma=\frac{\pi}{2}-\varphi
$$

The dowel force that can be anchored per bar results

$$
V_{\text {dow }}=f_{c t, e f f} A_{b, d o w}
$$

where $A_{b, \text { dow }}$ refers to the effective concrete area opposing to the force of one dowel ${ }^{6,8}$ (Fig. 13(a)). This area is calculated as the projection in the plane of the slab of the breakthrough surface $A_{b}$ (assumed as the total available area activated under the projection of $x_{h}+x_{h c}$ ) (Fig. 13(a)), divided upon the number of doweled sections $n_{\text {dow }}$ (Fig. 13(c))

$$
A_{b, \text { dow }}=\frac{\pi\left(\left(r_{c}+c_{d} \cot \alpha+x_{h}+x_{h c}\right)^{2}-\left(r_{c}+c_{d} \cot \alpha\right)^{2}\right)}{n_{\text {dow }}}
$$

Consistently with the work of Fernández Ruiz et al., ${ }^{7}$ the following equation is adopted for the evaluation of the effective tensile strength

$$
f_{c t, e f f} \approx 0.6 f_{c t}
$$

For the evaluation of $f_{c t}$, the influence of the concrete strength, aggregate size, and size effect shall be considered. This is proposed to be performed in the following manner

$$
f_{c t} \approx 0.5 \sqrt{f_{c}} \cdot k_{d}
$$

Expression in SI units (in case of customary units [psi], 0.5 has to be replaced by 6 ). In this equation, the term $k_{d}$ accounts for size effect and can be evaluated as

$$
k_{d}=\frac{2.5}{1+\frac{1}{5} \frac{d}{d_{g}+d_{g 0}}} \leq 1.2
$$

The values of $d_{g}$ and $d_{g 0}$ refer to, respectively, the maximum and reference aggregate sizes consistently with those defined in Eq. (1). Thus, the shear force that can be transferred by doweling action results eventually

$$
V_{\text {dow }}=0.3 \sqrt{f_{c}} \cdot k_{d} \cdot \frac{\pi\left(\left(r_{c}+c_{d} \cot \alpha+x_{h}+x_{h c}\right)^{2}-\left(r_{c}+c_{d} \cot \alpha\right)^{2}\right)}{n_{\text {dow }}}
$$

using SI units (in case of customary units [psi], 0.3 has to be replaced by 3.6).

The calculation of the maximum force that can be activated for a dowel can be performed by solving the set of Eq. (9) and (19). It can be noted that it is a set of nonlinear equations and requires to be solved by means of numerical means. 
Table 5-Comparison of experimental and calculated punching strengths

\begin{tabular}{c|c|c|c|c}
\hline Slab & $V_{R, \text { test }}$ MN (kip) & $\psi_{R}, \mathrm{mrad}$ & $\begin{array}{c}V_{R, \text { test }} / \\
V_{R, C S C T(\text { quadrilinear) }}\end{array}$ & $V_{R, \text { CSCT(parabolic) }}$ \\
\hline PL1 & $0.68(153)$ & 6.0 & 1.00 & 1.04 \\
\hline PV1 & $0.97(219)$ & 7.6 & 1.04 & 1.06 \\
\hline PL6 & $1.36(306)$ & 18.6 & 0.98 & 1.07 \\
\hline PL7 & $1.77(399)$ & 32.0 & 1.07 & 1.12 \\
\hline PC23 & $1.19(268)$ & 8.4 & 1.13 & 1.14 \\
\hline PC24 & $2.15(483)$ & 21.6 & 1.00 & 1.06 \\
\hline PC25 & $1.20(270)$ & 4.7 & 1.07 & 1.04 \\
\hline PC26 & $2.45(551)$ & 15.4 & 1.02 & 1.06 \\
\hline PP10 & $2.15(483)$ & 35.2 & 1.00 & 1.07 \\
\hline PP12 & $3.22(724)$ & 30.7 & 1.18 & 1.21 \\
\hline PP13 & $2.10(472)$ & 29.4 & 0.99 & 1.05 \\
\hline PP14 & $3.23(726)$ & 32.1 & 1.05 & 1.09 \\
\hline PP15 & $2.97(668)$ & 30.9 & 1.00 & 1.05 \\
\hline PP16 & $2.97(668)$ & 30.9 & 1.04 & 1.08 \\
\hline PP17 & $1.62(364)$ & 28.6 & 1.04 & 1.10 \\
\hline & Mean & & 1.04 & 1.08 \\
\hline
\end{tabular}

\section{Load-rotation relationship}

For the calculation of the failure load and of its associated deformation capacity, the failure criterion previously discussed has to be intercepted by the load-rotation relationship of the slab; refer to Fig. 12. To that aim, various approaches are possible $e^{11,24-26}$ and the estimate of the failure load can be considered as more accurate when more refined estimates of the actual behavior of the slab are considered. In the following, the load-rotation response of the slab will be calculated on the basis of the integration of a quadrilinear moment-curvature law (one of the most accurate approaches available), as proposed by Muttoni. ${ }^{11}$ In addition, the resistance will also be calculated by using the simplified parabolic load-rotation response developed by Muttoni ${ }^{11}$ for practical purposes (derived on the basis of the quadrilinear expression but adopting a parabolic law ( $3 / 2$ exponent) as a function of the ratio $V / V_{\text {flex }}$ ).

With respect to the flexural reinforcement amount, it is determined on the basis of the actual effective depth (Table 2) and considering, when applicable, the contribution of the top layers of double-headed studs (Specimens PP10, PP12, and PP14); refer to $d_{\text {avg }}$ in Table 4.

\section{Comparison to test results}

By using the failure criterion, Eq. (4), and the loadrotation relationship, the failure loads can be calculated. This is presented for all specimens in Fig. 14 for the refined model (Eq. (6) in Muttoni ${ }^{11}$ ) as well as for the simplified load-rotation curve (Eq. (8) in Muttoni ${ }^{11}$ ). The figure shows that both models finely reproduce the test results, with a consistent agreement in the failure load.
Table 6-Estimation of delamination length $x_{h}$ according to proposed mechanical model

\begin{tabular}{c|c|c}
\hline Slab & $d_{b, H H S}, \mathrm{~mm}(\mathrm{in})$. & $x_{h}, \mathrm{~mm}($ in. $)$ \\
\hline PP10 & $25(0.98)$ & $26.6(10.5)$ \\
\hline PP12 & $25(0.98)$ & $24.0(0.94)$ \\
\hline PP13 & $25(0.98)$ & $27.4(10.8)$ \\
\hline PP14 & $32(1.26)$ & $39.2(15.4)$ \\
\hline PP15 & $16(0.63)$ & $55.6(21.9)$ \\
\hline PP16 & $40(1.57)$ & $39.1(15.4)$ \\
\hline PP17 & $32(1.26)$ & $39.8(15.7)$ \\
\hline
\end{tabular}

(a)

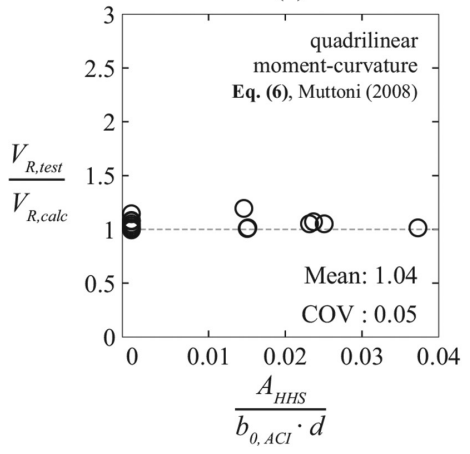

(b)

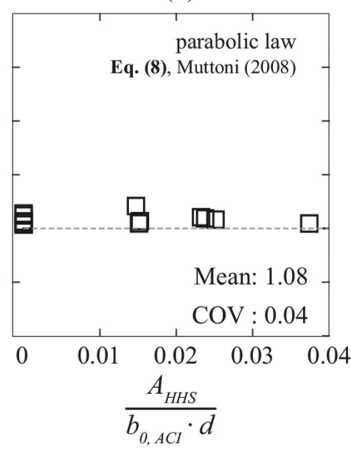

Fig. 14-Comparison of measured and calculated responses: (a) quadrilinear moment-curvature law (Eq. (6) in Muttoni ${ }^{11}$ ); and (b) parabolic law (Eq. (8) in Muttoni ${ }^{11}$ ).

The average of the measured-to-calculated punching strength results is, respectively, 1.04 and 1.08 with a coefficient of variation ranging between 4.2 and $5.3 \%$ (refer to Table 5). These values show sound agreement, with even lower scatter than for similar analyses on other punching reinforcing systems. ${ }^{12,13}$ The calculated delamination length (Table 6) resulting from the previous equations also shows reasonable values in fine agreement with the observed location in the saw-cuts (Fig. 7).

\section{CONCLUSIONS}

In this paper, a punching shear reinforcing system comprising the use of large-diameter horizontal doubleheaded studs (studs arranged parallel to the plane of the slab in the compression zone) as shear dowels is presented. The performance of the system is verified by means of a specific testing program and compared to that of geometrically equivalent slabs without shear reinforcement or with conventional shear reinforcement (shear reinforcement arranged perpendicular to the plane of the slab). Design for the system is eventually investigated on the basis of the Critical Shear Crack Theory (CSCT). The main conclusions of this investigation are:

1. The system exhibits a significantly enhanced performance in terms of the punching strength and deformation capacity (rotation at maximum load) when compared to slabs without shear reinforcement or with conventional shear reinforcement. For the tests presented in this paper, the failure load increases up to 250 to $270 \%$ of the strength corresponding to members without shear reinforcement. The 
deformation capacity increases also to more than $700 \%$ of the corresponding value for specimens without shear reinforcement. Such enhancement is higher than for members with conventional shear reinforcement composed only of vertical studs, particularly with respect to the deformation capacity (which can be doubled when horizontal studs are arranged in addition to vertical studs).

2. Horizontal double-headed studs are shown to be an efficient solution as shear dowels. They allow transferring shear forces, which reduce the amount of shear that has to be transferred by the critical shear crack, thus enhancing the strength of the specimen.

3. The activation of the horizontal shear dowels is related to a penetration of the column in the slab. This yields to a failure mode with an enhanced deformation capacity when compared to slabs without shear reinforcement or with conventional shear reinforcement.

4. A mechanical model based on the theoretical framework of the CSCT is presented. The model consistently accounts for the contribution of the shear dowels in the punching failure criterion.

5. The model based on the CSCT is shown to provide sound and accurate predictions when compared to test results on specimens reinforced with this system. It further allows investigating on the actual contribution of this reinforcement to the total strength and to calculate some mechanical parameters as the extent of the potential delamination due to bending of the shear dowel.

\section{AUTHOR BIOS}

Raffaele Cantone is PhD Student at École Polytechnique Fédérale de Lausanne (EPFL), Lausanne, Switzerland. He received his MS from the University of Parma, Parma, Italy, in 2015. His research interests include punching shear behavior of reinforced concrete slabs and internal force redistributions in slabs after cracking in bending and shear.

ACI member Miguel Fernández Ruiz is a Lecturer and Research Scientist at EPFL. He was the co-recipient of the ACI Wason Medal for Most Meritorious Paper in 2014. His research interests include the serviceability behavior of structures, bond, shear and punching shear, and the modeling of structural concrete using stress fields.

Jan Bujnak is a Research and Development Manager at Peikko Group Corporation, Lahti, Finland. He received his PhD from Polytech Clermont-Ferrand, Aubière, France, in 2007. His research interests include bond, fastening technology, and punching shear in flat slabs.

ACI member Aurelio Muttoni is a Professor and Head of the Structural Concrete Laboratory at EPFL. He was the recipient of the ACI Chester Paul Siess Award for Excellence in Structural Research in 2010 and the co-recipient of the Wason Medal for Most Meritorious Paper in 2014. His research interests include the theoretical bases of the design of reinforced concrete structures, shear and punching shear, fiber-reinforced highstrength concrete, soil-structure interaction, and the conceptual design of bridges.

\section{ACKNOWLEDGMENTS}

Peikko Group funded the experimental work presented in this paper. The authors would like to express their sincere gratitude for allowing them to publish the experimental data and for the support received.

$A_{b}=$ breakthrough surface

\section{NOTATION}

$A_{b, \text { dow }}=$ effective concrete area opposing to force of one dowel

$A_{H H S}=$ gross area of horizontal headed bars $(H H S)$

$B=$ side length of slab

$b_{0, \mathrm{ACI}}=$ perimeter of critical section according to ACI 318-14 $b_{e} \quad=$ width of equivalent section

$c \quad=$ side length of supporting area

$c_{d} \quad=$ distance between slab soffit and center of mass of HHS bars in bottom side

$c_{\text {nom }} \quad=$ nominal concrete cover

$d \quad=$ distance from extreme compression fiber to centroid of longitudinal tensile reinforcement

$d_{\text {avg }} \quad=$ nominal distance from extreme compression fiber to centroid of longitudinal tensile reinforcement in case of horizontal headed studs positioned in tensile zone

$d_{b} \quad=$ diameter of flexural reinforcement

$d_{b, H H S}=$ diameter of HHS bars

$d_{g} \quad=$ aggregate size

$d_{g 0} \quad=$ reference aggregate size

$d_{\text {nom }} \quad=$ nominal distance from extreme compression fiber to centroid of longitudinal tensile reinforcement

$d_{x} \quad=$ spacing between gauges glued in HHS bars

$f_{c} \quad=$ average compressive strength of concrete (cylinder)

$f_{c c} \quad=$ compressive strength of confined concrete

$f_{c t} \quad=$ concrete tensile strength

$f_{c t, e f f}=$ effective concrete tensile strength

$f_{y} \quad=$ yield strength of flexural reinforcement

$h_{f} \quad=$ height of bar carrying bending moment

$h_{\tau} \quad=$ height of bar carrying shear force

$l \quad=$ distance between plastic hinges

$M_{R} \quad=$ bending resistance of hinges

$n_{\text {dow }} \quad=$ number of doweled sections

$n_{r} \quad=$ number of radii of shear reinforcement

$n_{s} \quad=$ number of shear reinforcements per radius

$r_{q} \quad=$ distance between load introduction point and axis of supported area

$s_{0} \quad=$ nominal distance with respect to slab plane between edge of support region and first shear stud

$s_{1} \quad=$ nominal distance with respect to slab plane between two adjacent studs of same radius

$s_{H H S}=$ nominal distance between horizontal headed studs (HHS)

$V \quad=$ resultant shear force applied on supporting area

$V_{c} \quad=$ contribution of concrete

$V_{\text {dow }} \quad=$ contribution of doweling action calculated with limit analysis

$V_{n} \quad=$ punching capacity

$V_{n, \max } \quad=$ maximum punching capacity

$V_{R} \quad=$ punching shear strength

$V_{R, C S C T \text { (parabolic) }}=$ design punching capacity according to CSCT accounting for doweling action according to simplified parabolic law

$V_{R, C S C T \text { (quadrilinear) }}=$ design punching capacity according to CSCT accounting for doweling action according to quadrilinear moment-curvature

$V_{R, \text { calc }}=$ calculated/design punching capacity

$V_{R, \text { test }} \quad=$ experimental punching capacity

$V_{s} \quad=$ contribution of steel reinforcement

$x_{h} \quad=$ estimation of delamination length

$\alpha \quad=$ angle of critical shear crack

$\chi \quad=$ measured curvature of shear dowel

$\chi_{y} \quad=$ yielding curvature of shear dowel

$\varepsilon_{s} \quad=$ steel strain

$\varepsilon_{y} \quad=$ steel strain at yielding

$\gamma \quad=$ angle of concrete breakout surface

$\lambda=$ crushing strength parameter

$\rho_{l} \quad=$ flexural reinforcement ratio

$\rho_{w} \quad=$ shear reinforcement ratio

$\psi \quad=$ average of rotations at point of moment contraflexure

$\psi_{R} \quad=$ measured rotation at failure

\section{REFERENCES}

1. Kinnunen, S., and Nylander, H., Punching of Concrete Slabs without Shear Reinforcement, Elanders Boktryckeri Aktiebolag, 1960, 122 pp.

2. fib Bulletin 81, "Punching Shear of Structural Concrete Slabs: Honoring Neil M. Hawkins," ACI- fib Symposium Proceedings 378, 2017.

3. Einpaul, J.; Fernández Ruiz, M.; and Muttoni, A., "Influence of Moment Redistribution and Compressive Membrane Action on Punching Strength of Flat Slabs," Engineering Structures, V. 86, 2015, pp. 43-57. doi: 10.1016/j.engstruct.2014.12.032

4. Einpaul, J.; Ospina, C. E.; Fernández Ruiz, M.; and Muttoni, A., "Punching Shear Capacity of Continuous Slabs," ACI Structural Journal, V. 113, No. 4, July-Aug. 2016, pp. 861-872. doi: 10.14359/51688758 
5. Einpaul, J.; Brantschen, F.; Fernández Ruiz, M.; and Muttoni, A., "Performance of Punching Shear Reinforcement under Gravity Loading : Influence of Type and Detailing," ACI Structural Journal, V. 113, No. 4, July-Aug. 2016. doi: 10.14359/51688630

6. Mirzaei, Y., "Post-Punching Behavior of Reinforced Concrete Slabs,' $\mathrm{PhD}$ dissertation, École Polytechnique Fédérale de Lausanne École Polytechnique Fédérale de Lausanne, Lausanne, Switzerland, 2010, 230 pp.

7. Fernández Ruiz, M.; Mirzaei, Y.; and Muttoni, A., "Post-Punching Behavior of Flat Slabs," ACI Structural Journal, V. 110, No. 5, Sept.-Oct. 2013, pp. 801-812.

8. Habibi, F.; Cook, W. D.; and Mitchell, D., "Predicting Post-Punching Shear Response of Slab-Column Connections," ACI Structural Journal, V. 111, No. 1, Jan.-Feb. 2014, pp. 123-134.

9. Cavagnis, F.; Fernández Ruiz, M.; and Muttoni, A., “An Analysis of the Shear-Transfer Actions in Reinforced Concrete Members without Transverse Reinforcement Based on Refined Experimental Measurements," Structural Concrete, V. 19, No. 1, 2017, pp. 1-16. doi: 10.1002/ suco.201700145

10. Cavagnis, F.; Ruiz, M. F.; and Muttoni, A., "A Mechanical Model for Failures in Shear of Members without Transverse Reinforcement Based on Development of a Critical Shear Crack," Engineering Structures, V. 157, 2018, pp. 300-315. doi: 10.1016/j.engstruct.2017.12.004

11. Muttoni, A., "Punching Shear Strength of Reinforced Concrete Slabs without Transverse Reinforcement," ACI Structural Journal, V. 105, No. 4, July-Aug. 2008, pp. 440-450.

12. Ruiz, M. F., and Muttoni, A., "Applications of Critical Shear Crack Theory to Punching of Reinforced Concrete Slabs with Transverse Reinforcement," ACI Structural Journal, V. 106, No. 4, July-Aug. 2009, pp. 485-494.

13. Lips, S.; Ruiz, M. F.; and Muttoni, A., "Experimental Investigation on Punching Strength and Deformation Capacity of Shear-Reinforced Slabs," ACI Structural Journal, V. 109, No. 6, Nov.-Dec. 2013, pp. 889-900.

14. CEN 10080:2005, "Steel for the Reinforcement of Concrete - Weldable Reinforcing Steel - General," European Committee for Standardization, Brussels, Belgium, 2005.

15. Einpaul, J.; Bujnak, J.; Fernández Ruiz, M.; and Muttoni, A., "Study on Influence of Column Size and Slab Slenderness on Punching Strength," ACI Structural Journal, V. 113, No. 1, Jan.-Feb. 2016, pp. 135-145.
16. Simões, J. T.; Fernández Ruiz, M.; and Muttoni, A., "Validation of the Critical Shear Crack Theory for Punching of Slabs without Transverse Reinforcement by Means of a Refined Mechanical Model," Structural Concrete, V. 19, No. 1, 2018, pp. 191-216. doi: 10.1002/suco.201700280

17. Muttoni, A.; Fernández, M.; and Simões, J. T., "The Theoretical Principles of the Critical Shear Crack Theory for Punching Shear Failures and Derivation of Consistent Closed-Form Design Expressions," Structural Concrete, 2017, pp. 1-17.

18. Fernández Ruiz, M.; Muttoni, A.; and Kunz, J., "Strengthening of Flat Slabs against Punching Shear Using Post-Installed Shear Reinforcement," ACI Structural Journal, V. 107, No. 4, July-Aug. 2010, pp. 434-442.

19. Fernández Ruiz, M., and Muttoni, A., "Performance and Design of Punching Shear Reinforcing Systems," 3rd International fib Congress 15, 2010 .

20. Sørensen, J. H.; Herfelt, M. A.; Hoang, L. C.; and Muttoni, A., "Test and Lower Bound Modeling of Keyed Shear Connections in RC Shear Walls," Engineering Structures, V. 155, 2018, pp. 115-126. doi: 10.1016/j. engstruct.2017.11.004

21. Mises, R. V., "Mechanics of Plastic Deformation in Crystals," Math Mech, V. 8, 1928, pp. 161-185.

22. Rasmussen, B. H., Betonindstobte Tvaerbelastede Boltes og Dornes Baereevne, Bygningstatiske Meddelser, 1963.

23. Nielsen, M. P., and Hoang, L. C., Limit Analysis and Concrete Plasticity, CRC Press, Boca Raton, FL, 2016.

24. Muttoni, A.; Fernández Ruiz, M.; Bentz, E. C.; Foster, S. J.; and Sigrist, V., "Background to the Model Code 2010 Shear Provisions-Part II Punching Shear," Structural Concrete, V. 14, No. 3, 2013, pp. 195-203. doi: 10.1002/suco.201200064

25. Belletti, B.; Scolari, M.; Muttoni, A.; and Cantone, R., "Shear Strength Evaluation of RC Bridge Deck Slabs According to CSCT with Multi-Layered Shell Elements and PARC_CL Crack Model," IABSE Conference, Geneva, Switzerland, 2015, pp. 1158-1165.

26. Cantone, R.; Belletti, B.; Muttoni, A.; and Fernández Ruiz, M., "Approaches for Suitable Modelling and Strength Prediction of Reinforced Concrete Slabs," fib Symposium, 2016. 